\title{
Effects of Health Promotion Model-Based Visual Learning Module on Self-Efficacy and Health Promotion Behavior of Stroke Survivors: A Nonrandomized Controlled Trial
}

\author{
Shiv Kumar Mudgal ${ }^{1}$ Suresh K. Sharma ${ }^{2} \quad$ jitender Chaturvedi3,๑ Digpal Singh Chundawat ${ }^{4}$
}

${ }^{1}$ Akal College of Nursing, Eternal University, Baru Sahib, Himachal Pradesh, India

${ }^{2}$ College of Nursing, All India Institute of Medical Sciences, Rishikesh, Uttarakhand, India

${ }^{3}$ Department of Neurosurgery, All India Institute of Medical

Sciences, Rishikesh, Uttarakhand, India

${ }^{4}$ Department of Nursing, All India Institute of Medical Sciences,

Bhopal, Madhya Pradesh, India

\begin{abstract}
Address for correspondence Jitender Chaturvedi, MCh, Department of Neurosurgery, All India Institute of Medical Sciences, Rishikesh 249203, Uttarakhand, India (e-mail: drjittu28@gmail.com).
\end{abstract}

\begin{abstract}
Background and Objectives Globally, stroke is one of the major causes of disability and mortality among adults and old age people. The present study aims to evaluate the effects of the health promotion model-based visual learning module (HPM-VLM) on self-efficacy and behavioral modifications among stroke survivors.

Methods This nonrandomized controlled trial was conducted on 70 stroke survivors (intervention group, $n=35$, and control group, $n=35$ ). The intervention group was subjected to two sessions of the HPM-VLM and the control group received routine instructions. Data were collected through face-to-face structured interview, and observation using a self-structured self-efficacy questionnaire and health promotion behavior questionnaire. Data were analyzed using descriptive (frequency and percentage) and inferential (Chi-square, independent $t$-test, mixed model, and ANCOVA) values by IBM Statistical Package for Social Sciences (SPSS; version 23) software.

Keywords Results Eventually, follow-up could have been completed for 66 participants (inter-

- health promotion vention group, $n=34$, and control group, $n=32$ ). HPM-VLM is found to be effective in behavior the promotion of self-efficacy $(19.2 \pm 1.6$ vs. $16.12 \pm 2.5 ; p=001)$ and health promo-

- self-efficacy

- stroke

- survivors tion behavior of stroke survivors in most of the domains $(p<0.01)$.

Conclusion HPM-VLM is an effective interventional tool for the promotion of self-efficacy and health promotion behavior of stroke survivors.
\end{abstract}

\section{Introduction}

Stroke, a cerebrovascular disorder, is a clinical syndrome and considered as the second leading cause of mortality and persisting functional disability. ${ }^{1}$ In 2017, it was reported by World Health Organization (WHO) that between 20 and 50\% of stroke patients may be at the risk of death, which is directly associated with stroke severity, age of patients, presence of
DOI https://doi.org/ 10.1055/s-0041-1727407 ISSN 0976-3147
(C)2021. Association for Helping Neurosurgical Sick People.

This is an open access article published by Thieme under the terms of the Creative Commons Attribution-NonDerivative-NonCommercial-License, permitting copying and reproduction so long as the original work is given appropriate credit. Contents may not be used for commercial purposes, or adapted, remixed, transformed or built upon. (https://creativecommons.org/licenses/by-nc-nd/4.0/). Thieme Medical and Scientific Publishers Pvt. Ltd. A-12, 2nd Floor, Sector 2, Noida-201301 UP, India 
comorbidities, and management of stroke. ${ }^{2}$ It was reported that 15 to $30 \%$ of stroke survivors live with a permanent disability. Furthermore, $32 \%$ and $26 \%$ of patients require home health care management and long-term care, respectively. ${ }^{3}$

In India, 1.8 million people are admitted to hospital due to stroke every year and the estimated incidence of stroke was 119 to 1,125 per 100,000 people. It was also reported by the Indian Stroke Association that the stroke disease burden in India has raised approximately $100 \%$ in the last two decades while the developed countries have shown a reduction by $42 \%{ }^{4}$ It is reported in a study that approximately $25 \%$ of stroke patients required readmission within 12 weeks of discharge because of recurrence of stroke and patients with recurrent stroke had a higher mortality rate and more severe disability than those patients who suffered from stroke for the first time. ${ }^{4-7}$

Therefore, it is much more needed that stroke patients should get accurate information and living assistance to prevent stroke recurrence and decrease stroke care burden. ${ }^{1}$ Stroke literacy is one fundamental method for enhancing knowledge, developing healthy behavior, and a positive attitude to decrease the risks of stroke recurrence and mortality. Unfortunately, technology-based health education has not yet been used in routine conditions before the patient discharge. ${ }^{8}$ In the health care industry, radical changes are befalling because of continuous technological development to fulfill the ever-changing health-related demands of the patients. ${ }^{9}$ Hence, the visual learning module may be a fruitful and practical approach to health education.

Making positive changes in patients' perception and behavior toward the disease is deemed as an essential part of stroke prevention, treatment, and rehabilitation. Enhancing and sustaining positive perception is a complex phenomenon and the changes in behavior and perception are not easy because it requires a lot of motivation and knowledge to deal with the disease. Health care professionals can provide health education about health-promoting behaviors to their patients so that they can manage the post-stroke period effectively and prevent the recurrence of stroke. ${ }^{10}$ Health promotion models like Pender's Health Promotion Model (HPM) is a beneficial and appropriate framework, which provides a path for health care professionals to plan and implement their strategies effectively. ${ }^{11}$ Several studies investigated the effectiveness of various methods based on HPM for enhancing and maintaining healthy behaviors ${ }^{10,12,14}$ but studies based on HPM conducted among stroke patients are very limited. Considering the absolute need of health-promoting behavior in stroke patients and the role of HPM-based education in changing perception and enhancing health-promoting behaviors, the investigators planned to carry out a study to ascertain the effectiveness of a health promotion model-based visual learning module (HPM-VLM) on self-efficacy and health promotion behavior modifications in stroke survivors.

\section{Methodology}

This pretest-post-test control group nonrandomized study was performed on adult stroke patients from two tertiary care centers in Udaipur city, India, from March 2018 to June 2018. The sample size was estimated by using Equation; $2 \times(\mathrm{Z} 1-\beta+\mathrm{Z} 1-\alpha / 2) 2(\mathrm{SD} / \mathrm{d}) 2$ and considering $\alpha=0.05$, $\beta=0.80$, and $10 \%$ drop out rate. ${ }^{13}$ The pooled standard deviation (0.68) and mean difference (0.129) were calculated from the results of the pilot study. The estimated sample size was 70 participants.

Ethical approval was obtained from the Institutional Ethics Committee vide letter no. PMCH/IEC/20/2127 dated September 02, 2018. The purpose of the study was well informed to all the participants and all of them were anonymized by name and institute. An informed written consent was taken from each participant.

The study participants who were enrolled in the present study fulfilled the following eligibility criteria: (1) age $\geq 18$ years, (2) stroke diagnosed and confirmed by neurologist, (3) able to communicate, (4) Mini-Mental State Examination Score $\geq 24$, (5) agree to take part in the present study. We excluded the participants on the following criteria: (1) being a health care professional (doctors/nurses/technicians/pharmacists), (2) unable to follow the researcher's instructions or Glasgow Coma Scale Score $\leq 13$, (3) presence of conditions like delirium, dementia, or aphasia. Seventy eligible participants were assigned to intervention (35) and control (35) groups (-Fig. 1).

After allocating the participants into control and intervention, the pretest was organized for both groups. HPM-VLM was developed. After getting approval from competent authorities (Medical Superintendent, Nursing Superintendent, and Head of Stroke Units), the control group received routine discharge education as per institution protocol. However, participants in the intervention group received two sessions of HPM-VLM for 45 to 60 minutes using discussion and demonstration methods with question-answer sessions. Furthermore, video and written materials on stroke were also provided to these participants. After 4 and 12 weeks of the second session, a post-test was given to both the groups. As per good clinical practice guidelines, the training material was provided to the participants of the control group after the post-test.

The data were collected using a health promotion behavior modification questionnaire and a self-structured self-efficacy questionnaire. The self-structured self-efficacy questionnaire had two parts. Section A: eleven questions related to demographic characteristics of participants such as age, gender, marital status, types of stroke, previous history of stroke, previous history of myocardial infarction, cholesterol level, history of comorbidities, history of smoking, family history of stroke, and severity of stroke. Section B: it is made up of 33 items and was based on stroke-related content. Each right and wrong answer was assigned "one mark" and "zero marks," respectively. The total maximum and minimum scores were 33 and 0 , respectively. The higher score suggested better self-efficacy therefore, a higher post-test score than the pretest score, indicated that participants' behavior was modified on self-efficacy.

The research team also developed a questionnaire based on the health promotional model, which included 61 items and eight subscales. These subscales were: perceived 


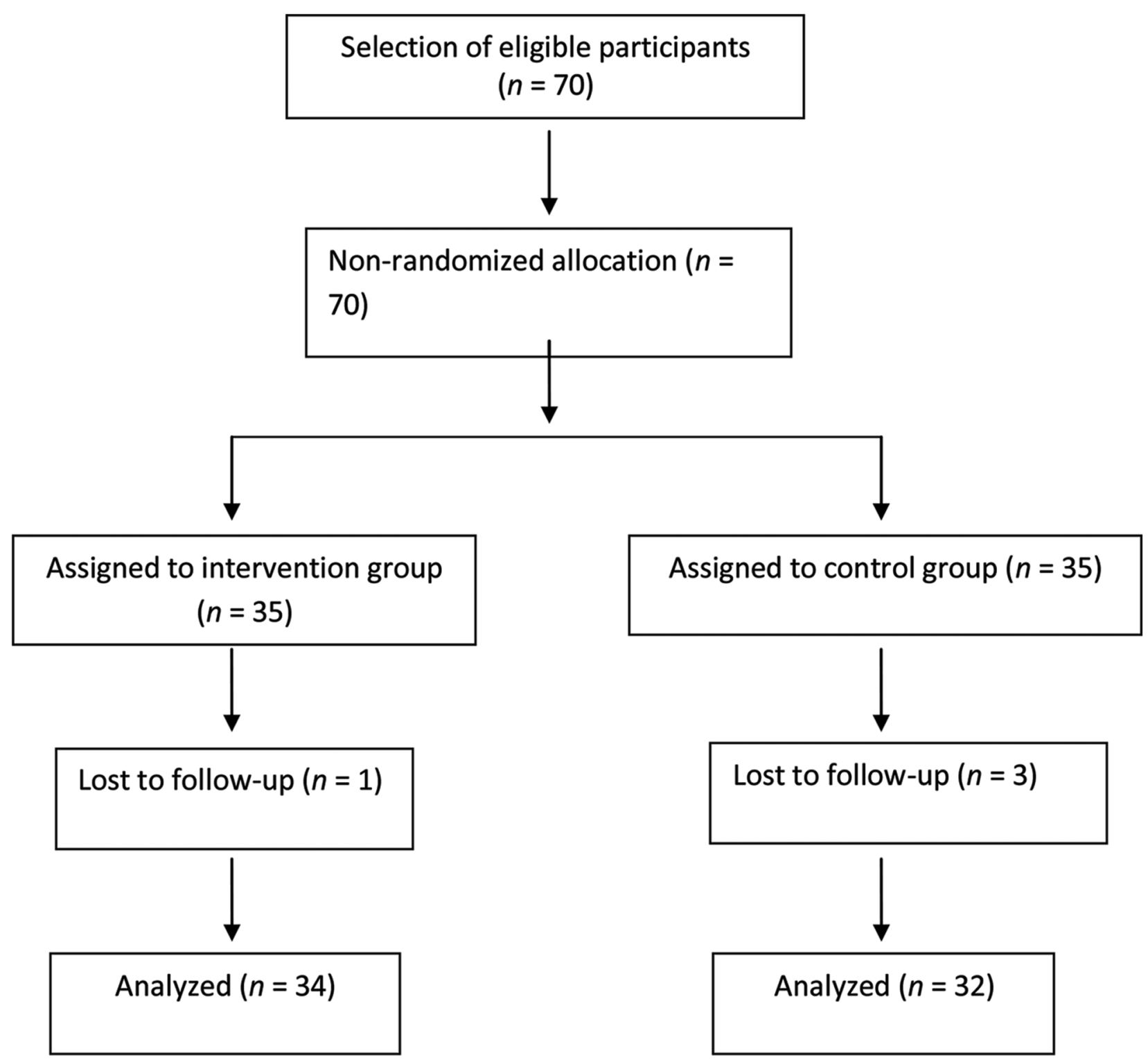

Fig. 1 Flow of participants' selection and study completion according to transparent reporting of evaluations with nonrandomized designs statement.

behavior-specific feeling and knowledge (six statements), perceived benefits (six statements), perceived barriers (eight statements), perceived self-efficacy (eight statements), activity-related effects (12 statements), interpersonal and situational influence (12 and three statements, respectively), and commitment to action (six statements). Each item in the health promotion behavior questionnaire was scored on a 5-point Likert Scale. Each positive item had a minimum of 1 mark and a maximum of 5 marks for strongly disagreeing and strongly agreeing, respectively, while for negative item scoring was done in reverse manner.

The content validity of the self-efficacy questionnaire and health promotion behavioral questionnaire was determined by sending them to a panel of experts. This panel included nine members of experts (five nursing administrators and faculties, three neurophysicians, and one physiotherapist) and who were requested to give their comments. Based on experts' comments and feedback, item content validity index was calculated, and desired modifications were done to make a final version of both the questionnaires. Internal consistency for both the questionnaires was determined by using Cronbach's $\alpha$ coefficient and it was found 0.88 for self-efficacy questionnaire and 0.81 for health promotion behavioral questionnaire which indicated that both the questionnaires were reliable. HPM-VLM content was also validated from the same validators.

We used SPSS (version 23.0, IBM Statistics) for data analysis. We performed a Chi-square and student $t$-test to compare the baseline characteristics of the participants in intervention and control groups. Data before and after intervention on participants' self-efficacy were compared by using student $t$-test, linear mixed model for repeated measurements, and analysis of covariance (ANCOVA). We set the statistical 
significance level at $p<0.05$ and 95\% confidence interval was used.

\section{Results}

In the present study, 70 stroke survivors participated. The participants' mean \pm SD age was $56.129 \pm 9.812$ and 58.09 \pm 9.07 years in intervention and control groups $(p=0.1282)$, respectively. Most of the participants were male (62.66\%), had an ischemic stroke (77.14\%), married (85.71\%), had a history of smoking (60.0\%), myocardial infarction (15.7\%), high cholesterol level (75.7\%), and all had a history of comorbidities (100\%). More than one-third (37.1) participants were in level two on modified Rankin scale level. With regard to demographic and clinical characteristics of participants, no statistically significant intergroup differences were found (all $p>0.05$; - Table 1 ).

The study observed no significant intergroup differences before intervention ( $p=0.188$ ) on self-efficacy. However, after 4 and 12 weeks of intervention, a statistically significant intergroup difference was found $\left(t_{68}=12.012 ; p=0.000\right)$. In terms of health promotion behavior, the findings of present study discovered no significant difference between the two groups before intervention. While 4 and 12 weeks after the intervention, in all health promotion behavior domains, except for the interpersonal influence $(p=0.737)$ significant differences were observed between the groups (-Table 2 ).

- Table 3 presents the results from the mixed model analysis and revealed no statistical significant difference in control group except perceived benefits $(p=0.000)$ and activity-related effect construct $(p=0.03)$ at 4 th and 12 th weeks post intervention respectively while in intervention group all health promotion behavior constructs and overall efficacy were changed significantly except at interpersonal influence construct at 4th and 12th week after intervention. There was a significant difference between the groups at 4th and 12th weeks post intervention except interpersonal influence construct ( $p=0.825 ; 0.907$ ).

The impact of score before intervention was controlled by ANCOVA at overall self-efficacy and all health promotion behavior constructs with etiology of stroke. - Table $\mathbf{4}$ shows more details.

With regard to caregivers' satisfaction or usefulness with HPM-VLM, almost all (91.2\%) of the caregivers found HPM-VLM useful in terms of enhancing self-efficacy and health promotion behavior of their patients and they were satisfied with it (-Fig. 2).

\section{Discussion}

In the present study, we assessed the effect of the HPM-VLM on stroke survivors' self-efficacy and health promotion behavior. The modified healthy behavior helps in the prevention of stroke recurrence and effective management of post-stroke rehabilitation. Self-efficacy is a crucial element of behavior modification. Therefore, enhancing self-efficacy could be a way to develop and sustain healthy behavior in stroke survivors. ${ }^{15}$ The present study showed the effect of HPM-VLM on increasing stroke survivors' self-efficacy and almost all HPM constructs. Reviewing the literature, we did not retrieve any related article on the efficiency of HPM-VLM on stroke survivors' self-efficacy and health promotion behavior constructs.

However, it was identified that the overall score of the intervention group was significantly increased compared with the control group after intervention. These results support that HPM-VLM was an effective method in enhancing literacy regarding stroke. The results of the present study go by the findings by Wang et $\mathrm{al}^{16}$ in which they presented that there was an improvement in self-efficacy and exercise patterns among participants who received an HPM-based health promotion program. Furthermore, our results are also consistent with the findings of Gomes Guedes et ale's study. ${ }^{17}$

The findings of our study revealed that participants' activity-related effects enhanced significantly in the intervention group when compared with the control group. The findings of our study are in the loop with studies conducted by Heydari et $\mathrm{l}^{18}$ and Taymoori et $\mathrm{al}^{19}$ where they reported that participants' level of physical activity significantly increased in the intervention group after application of model-based education. These findings indicated that education based on models or theories may change the individual behavior and strengthen healthy behavior through modification of important, influential, and selective components of behavior.

Results of the present study reported that perceived benefits to stroke literacy enhanced after HPM-VLM in the intervention group that suggested intervention built on HPM can change individuals' beliefs. This would be beneficial to them for control of risk factors and prevention of stroke recurrence effectively. These findings are corresponding to studies performed by Zamani et $\mathrm{al}^{20}$ and Rahimian et $\mathrm{al}^{21}$ where they reported that model-based intervention had a positive impact among study participants on developing and sustaining positive attitude toward desired behaviors.

Findings also suggested that perceived barriers to self-efficacy decreased significantly in the intervention group which was as per another study conducted by Mohamadian et $\mathrm{al}^{22}$ and reported that perceived barriers decreased in the intervention group after intervention. This means that after HPM-VLM, participants developed a strong belief that they can overcome the obstacles in the way of stroke management. It was reported that perceived barriers influence the intention to develop and sustain healthy behavior. ${ }^{23}$ A study performed by McGuire et $\mathrm{al}^{24}$ revealed that perceived barriers were crucial elements in the development and compliance of healthy lifestyle behaviors. Therefore, it is needed to assess the perceived barriers and make strategies to reduce the perceived barriers to healthy actions.

In the present study, components of health promotion behavior like self-efficacy, activity, situational influence, and commitment to actions changed significantly in the intervention group when compared with the control group after HPM-VLM. Sevinç and Argon ${ }^{25}$ in her study also presented similar findings that participants who received the intervention based on HPM showed significant improvement in their self-efficacy, risk reduction, and functional capacity, which were in accordance with the results of our study. Besides, 
Table 1 Demographic and morbidity profile of participants

\begin{tabular}{|c|c|c|c|c|}
\hline Variable & $\begin{array}{l}\text { Intervention }(n=35) \\
\text { Frequency }(\%)\end{array}$ & $\begin{array}{l}\text { Control }(n=35) \\
\text { Frequency }(\%)\end{array}$ & $X^{2 / t}$ & $p$-Value \\
\hline $\mathrm{Age}^{\mathrm{a}}$ & $56.49 \pm 9.84$ & $58.09 \pm 9.07$ & 0.707 & $0.482^{b}$ \\
\hline \multicolumn{3}{|l|}{ Gender } & \multirow[t]{3}{*}{0.543} & \multirow[t]{3}{*}{$0.461^{c}$} \\
\hline Male & $23(65.7)$ & $21(60.0)$ & & \\
\hline Female & $12(34.3)$ & $14(40.0)$ & & \\
\hline \multicolumn{3}{|l|}{ Marital status } & \multirow[t]{3}{*}{0.467} & \multirow[t]{3}{*}{$0.495^{c}$} \\
\hline Married & $29(82.9)$ & $31(88.6)$ & & \\
\hline Widow/ & $06(17.1)$ & $04(11.4)$ & & \\
\hline \multicolumn{3}{|l|}{ Previous history of stroke } & \multirow[t]{3}{*}{0.108} & \multirow[t]{3}{*}{$0.743^{c}$} \\
\hline Yes & $07(20)$ & $5(14.3)$ & & \\
\hline No & $28(80)$ & $30(85.7)$ & & \\
\hline \multicolumn{3}{|l|}{ Family history of stroke } & \multirow[t]{3}{*}{0.128} & \multirow[t]{3}{*}{$0.721^{c}$} \\
\hline Yes & $05(14.3)$ & $4(11.4)$ & & \\
\hline No & $30(85.7)$ & $31(88.6)$ & & \\
\hline \multicolumn{3}{|l|}{ History of MI } & \multirow[t]{3}{*}{0.108} & \multirow[t]{3}{*}{$0.743^{c}$} \\
\hline Yes & $05(14.3)$ & $06(17.1)$ & & \\
\hline No & $30(85.7)$ & $29(82.9)$ & & \\
\hline \multicolumn{3}{|l|}{ High cholesterol level } & \multirow[t]{3}{*}{0.078} & \multirow[t]{3}{*}{$0.780^{c}$} \\
\hline Yes & $27(77.2)$ & $26(74.3)$ & & \\
\hline No & $08(22.8)$ & $09(25.7)$ & & \\
\hline \multicolumn{3}{|l|}{ Presence of comorbidities } & \multirow[t]{4}{*}{0.00} & \multirow[t]{4}{*}{$0.891^{c}$} \\
\hline Diabetes & $10(28.6)$ & $09(25.7)$ & & \\
\hline Hypertension & $17(48.6)$ & $19(54.3)$ & & \\
\hline Both & $08(22.8)$ & $07(20)$ & & \\
\hline \multicolumn{3}{|l|}{ History of smoking } & \multirow[t]{3}{*}{0.060} & \multirow[t]{3}{*}{$0.806^{c}$} \\
\hline Yes & $22(62.9)$ & $21(60.0)$ & & \\
\hline No & $13(37.1)$ & $14(40.0)$ & & \\
\hline \multicolumn{3}{|l|}{ Type of stroke } & \multirow[t]{3}{*}{0.324} & \multirow[t]{3}{*}{$0.569^{c}$} \\
\hline Ischemic & $26(74.3)$ & $28(80.0)$ & & \\
\hline Hemorrhagic & $09(25.7)$ & $07(20.0)$ & & \\
\hline \multicolumn{3}{|l|}{ Modified Rankin Scale Level } & \multirow[t]{5}{*}{0.290} & $0.962^{c}$ \\
\hline 1 & $9(25.7)$ & $8(22.9)$ & & \\
\hline 2 & $12(34.3)$ & $14(40.0)$ & & \\
\hline 3 & $7(20.0)$ & $7(20.0)$ & & \\
\hline 4 & $7(20.0)$ & $6(17.1)$ & & \\
\hline
\end{tabular}

Note: Significant at $p$-value $\leq 0.05$.

aData were mean \pm standard deviation.

bIndependent $t$-test.

'Chi-square.

Khodaveisi et $\mathrm{al}^{26}$ reported that after an HPM-based intervention there was a significant improvement in the intervention group on perceived self-efficacy, nutritional behavior, and other HPM constructs.

The results of previous studies revealed that the perception of the problem's severity could contribute to lifestyle modification among patients suffering from chronic diseases like diabetes, hypertension, coronary artery disease, and stroke. ${ }^{27,28}$ The results of our study was also in loop with another study conducted which showed that intervention based on health belief model was effective and improve HBM variables like perceived benefits, perceived barriers, and self-efficacy in intervention group after intervention $(p<0.05)$, while there were no statistical significant differences identified in control group between baseline and post-intervention follow-up. ${ }^{29}$

Family caregivers' good knowledge and skill regarding care for post-stroke patients deemed necessary for the care and rehabilitation of patients after stroke, particularly for preventing recurrence of stroke, feeding, and preventing 
Table 2 Comparison of overall self-efficacy score and health promotion behavior scores of the participants

\begin{tabular}{|c|c|c|c|c|}
\hline Variables & $\begin{array}{l}\text { Intervention } \\
(n=34) \\
\text { Mean } \pm \text { SD }\end{array}$ & $\begin{array}{l}\text { Control }(n=32) \\
\text { Mean } \pm \text { SD }\end{array}$ & $t / p$-Value & $95 \% \mathrm{Cl}$ \\
\hline \multicolumn{5}{|l|}{ Overall self-efficacy } \\
\hline Pre-intervention & $16.27 \pm 1.59$ & $15.73 \pm 1.51$ & $1.33 / 0.188$ & $0.269,1.34$ \\
\hline Post-intervention (at 4 wk) & $19.23 \pm 1.57$ & $16.36 \pm 2.54$ & $4.04 / 0.000$ & $1.45,4.28$ \\
\hline Post-intervention (at 12 wk) & $18.67 \pm 1.48$ & $16.23 \pm 3.55$ & $3.45 / 0.001$ & $1.03,3.84$ \\
\hline \multicolumn{5}{|l|}{ Health promotion behavior } \\
\hline \multicolumn{5}{|c|}{ 1. Perceived behavior specific feelings } \\
\hline Pre-intervention & $19.60 \pm 1.19$ & $19.56 \pm 1.04$ & $0.008 / 0.909$ & $0.544,0.611$ \\
\hline Post-intervention (at 4 wk) & $20.77 \pm 1.76$ & $19.66 \pm 1.27$ & $2.78 / 0.007$ & $0.308,1.89$ \\
\hline Post-intervention (at 12 wk) & $20.61 \pm 1.63$ & $19.76 \pm 1.22$ & $2.24 / 0.03$ & $0.088,1.578$ \\
\hline \multicolumn{5}{|l|}{ 2. Perceived benefits } \\
\hline Pre-intervention & $25.5 \pm 2.85$ & $25.33 \pm 2.79$ & $0.229 / 0.820$ & $1.29,1.63$ \\
\hline Post-intervention (at 4 wk) & $27.63 \pm 3.17$ & $25.53 \pm 2.94$ & $2.66 / 0.010$ & $0.519,3.68$ \\
\hline Post-intervention (at 12 wk) & $28.07 \pm 3.37$ & $25.70 \pm 2.78$ & $2.965 / 0.004$ & $0.769,3.964$ \\
\hline \multicolumn{5}{|l|}{ 3. Perceived barriers } \\
\hline Pre-intervention & $19.23 \pm 1.77$ & $19.03 \pm 1.73$ & $0.442 / 0.66$ & $0.706,1.106$ \\
\hline Post-intervention (at 4 wk) & $28.13 \pm 5.57$ & $19.10 \pm 1.86$ & $8.42 / 0.000$ & $6.88,11.18$ \\
\hline Post-intervention (at 12 wk) & $27.83 \pm 5.68$ & $19.00 \pm 1.68$ & $8.157 / 0.000$ & $6.66,11.00$ \\
\hline \multicolumn{5}{|l|}{ 4. Perceived self-efficacy } \\
\hline Pre-intervention & $16.27 \pm 2.11$ & $16.17 \pm 2.21$ & $0.179 / 0.859$ & $1.02,1.22$ \\
\hline Post-intervention (at 4 wk) & $29.30 \pm 2.63$ & $16.37 \pm 2.01$ & $21.41 / 0.000$ & $11.72,14.14$ \\
\hline Post-intervention (at 12 wk) & $27.97 \pm 2.91$ & $15.93 \pm 1.98$ & $18.68 / 0.000$ & $10.74,13.32$ \\
\hline \multicolumn{5}{|l|}{ 5. Activity-related effect } \\
\hline Pre-intervention & $8.30 \pm 1.78$ & $8.13 \pm 1.67$ & $0.373 / 0.711$ & $0.728,1.061$ \\
\hline Post-intervention (at 4 wk) & $12.83 \pm 2.36$ & $8.30 \pm 1.76$ & $8.42 / 0.000$ & $3.45,5.611$ \\
\hline Post-intervention (at 12 wk) & $12.70 \pm 2.32$ & $8.40 \pm 1.79$ & $8.03 / 0.000$ & $3.22,5.37$ \\
\hline \multicolumn{5}{|l|}{ 6. Interpersonal influence } \\
\hline Pre-intervention & $12.40 \pm 3.01$ & $12.10 \pm 3.14$ & $0.377 / 0.707$ & $1.291,1.891$ \\
\hline Post-intervention (at 4 wk) & $12.57 \pm 2.95$ & $12.23 \pm 3.09$ & $0.427 / 0.671$ & $1.23,1.90$ \\
\hline Post-intervention (at 12 wk) & $12.21 \pm 2.84$ & $11.90 \pm 3.29$ & $0.419 / 0.677$ & $1.258,1.925$ \\
\hline \multicolumn{5}{|l|}{ 7. Situational influence } \\
\hline Pre-intervention & $5.73 \pm 1.85$ & $5.40 \pm 1.79$ & $0.708 / 0.482$ & $0.609,1.276$ \\
\hline Post-intervention (at 4 wk) & $7.13 \pm 2.06$ & $5.61 \pm 1.78$ & $3.073 / 0.003$ & $0.534,2.532$ \\
\hline Post-intervention (at $12 \mathrm{wk}$ ) & $7.47 \pm 2.21$ & $5.97 \pm 1.86$ & $2.842 / 0.006$ & $0.443,2.556$ \\
\hline \multicolumn{5}{|l|}{ 8. Commitment to action } \\
\hline Pre-intervention & $11.03 \pm 2.44$ & $10.83 \pm 2.30$ & $0.326 / 0.745$ & $1.027,1.427$ \\
\hline Post-intervention (at 4 wk) & $16.11 \pm 4.18$ & $11.20 \pm 2.42$ & $5.44 / 0.000$ & $3.034,6.565$ \\
\hline Post-intervention (at 12 wk) & $14.76 \pm 2.83$ & $10.97 \pm 2.09$ & $5.905 / 0.000$ & $2.511,5.088$ \\
\hline
\end{tabular}

Abbreviations: $\mathrm{Cl}$, class Interval; SD, standard deviation; $t$, independent $t$-test. Note: Significant at $p$-value $\leq 0.05$.

complications, such as aspiration pneumonia, pressure ulcer prevention along with the initiation of early rehabilitation program. The results of our study illustrated that caregivers of intervention group were satisfied and found HPM-VLM as an effective measure to develop their understanding about stroke and patients care. The findings of our study were consistent with a study performed by Pitthayapong et $\mathrm{al}^{30}$ which showed that caregivers in the intervention group significantly improved their knowledge and skills on stroke care when compared with the control group.

The present study has a few limitations which are required to be considered. First, lack of participants' 
Visual Learning Module in Stroke Mudgal et al. 395

Table 3 Changes in mean scores from pre-intervention to post-intervention at 4th and 12th weeks of the participants

\begin{tabular}{|c|c|c|c|c|c|c|}
\hline \multirow[t]{3}{*}{ Variables } & \multicolumn{3}{|c|}{ Post-intervention follow-up (4th wk) } & \multicolumn{3}{|c|}{ Post-intervention follow-up (12th wk) } \\
\hline & \multicolumn{2}{|c|}{ Within group } & \multirow[t]{2}{*}{$\mathrm{B} / \mathrm{w}$ group } & \multicolumn{2}{|c|}{ Within group } & \multirow[t]{2}{*}{$B / w$ group } \\
\hline & Int. gr. & Con. gr. & & Int. gr. & Con. gr. & \\
\hline \multicolumn{7}{|l|}{ Overall self-efficacy } \\
\hline Mean difference & 2.966 & 0.633 & 2.333 & 2.400 & 0.500 & 1.90 \\
\hline $\mathrm{Cl}$ & $3.55,2.37$ & $1.96,0.70$ & $3.76,0.90$ & $3.02,1.77$ & $1.84,0.84$ & $3.34,0.45$ \\
\hline$p$-Value & 0.000 & 0.340 & 0.002 & 0.000 & 0.452 & 0.011 \\
\hline \multicolumn{7}{|c|}{ Health promotion behavior } \\
\hline \multicolumn{7}{|c|}{$\begin{array}{l}\text { 1. Perceived behavior } \\
\text { specific feelings }\end{array}$} \\
\hline Mean difference & 1.167 & 0.10 & 1.067 & 1.00 & 0.20 & 0.80 \\
\hline $\mathrm{Cl}$ & $1.55,0.77$ & $0.30,0.10$ & $1.50,0.63$ & $1.36,0.63$ & $0.42,0.02$ & $1.22,0.37$ \\
\hline$p$-Value & 0.000 & 0.326 & 0.000 & 0.000 & 0.083 & 0.000 \\
\hline \multicolumn{7}{|l|}{ 2. Perceived benefits } \\
\hline Mean difference & 2.133 & 0.200 & 1.933 & 2.566 & 0.366 & 2.200 \\
\hline $\mathrm{Cl}$ & $2.81,1.44$ & $0.57,0.17$ & $2.69,1.17$ & $3.34,1.79$ & $0.71,0.02$ & $3.03,1.36$ \\
\hline$p$-Value & 0.000 & 0.000 & 0.000 & 0.000 & 0.059 & 0.000 \\
\hline \multicolumn{7}{|l|}{ 3. Perceived barriers } \\
\hline Mean difference & 8.900 & 0.066 & 8.833 & 8.60 & 0.033 & 8.633 \\
\hline $\mathrm{Cl}$ & $11.1,6.71$ & $0.34,0.20$ & $10.9,6.67$ & $10.8,6.34$ & $0.19,0.26$ & $10.8,6.41$ \\
\hline$p$-Value & 0.000 & 0.625 & 0.000 & 0.000 & 0.769 & 0.000 \\
\hline \multicolumn{7}{|c|}{ 4. Perceived self-efficacy } \\
\hline Mean difference & 10.98 & 0.233 & 11.933 & 11.70 & 0.203 & 11.63 \\
\hline $\mathrm{Cl}$ & $11.8,9.96$ & $0.47,0.93$ & $13.2,10.7$ & $12.7,10.2$ & $0.43,0.86$ & $12.6,9.86$ \\
\hline$p$-Value & 0.000 & 0.504 & 0.000 & 0.000 & 0.498 & 0.000 \\
\hline \multicolumn{7}{|c|}{ 5. Activity-related effect } \\
\hline Mean difference & 4.533 & 0.166 & 4.367 & 4.40 & 0.266 & 4.133 \\
\hline $\mathrm{Cl}$ & $5.38,3.68$ & $0.36,0.03$ & $5.22,3.51$ & $5.22,3.57$ & $0.5,0.02$ & $4.97,3.29$ \\
\hline$p$-Value & 0.000 & 0.096 & 0.000 & 0.000 & 0.03 & 0.000 \\
\hline \multicolumn{7}{|l|}{$\begin{array}{l}\text { 6. Interpersonal } \\
\text { influence }\end{array}$} \\
\hline Mean difference & -0.166 & 0.133 & 0.033 & 0.166 & 0.200 & 0.033 \\
\hline $\mathrm{Cl}$ & $0.41,0.75$ & $0.32,0.05$ & $0.33,0.26$ & $0.21,0.54$ & $0.24,0.64$ & $0.60,0.53$ \\
\hline$p$-Value & 0.169 & 0.161 & 0.825 & 0.378 & 0.363 & 0.907 \\
\hline \multicolumn{7}{|c|}{ 7. Situational influence } \\
\hline Mean difference & 1.400 & 0.200 & 1.20 & 1.733 & 0.566 & 1.166 \\
\hline $\mathrm{Cl}$ & $1.98,0.81$ & $040,0.005$ & $1.80,0.59$ & $2.50,0.96$ & $1.06,0.6$ & $2.06,0.26$ \\
\hline p-Value & 0.000 & 0.058 & 0.000 & 0.000 & 0.027 & 0.000 \\
\hline \multicolumn{7}{|l|}{$\begin{array}{l}\text { 8. Commitment to } \\
\text { action }\end{array}$} \\
\hline Mean difference & 4.966 & 0.366 & 4.601 & 3.733 & 0.133 & 3.60 \\
\hline $\mathrm{Cl}$ & $6.33,3.60$ & $0.69,0.3$ & $5.97,3.22$ & $4.89,2.57$ & $0.53,0.26$ & $4.80,2.39$ \\
\hline$p$-Value & 0.000 & 0.32 & 0.000 & 0.000 & 0.502 & 0.000 \\
\hline
\end{tabular}

Abbreviations: B/w, between; $\mathrm{Cl}$, class Interval; Con. gr., control group; Int. gr., intervention group.

Note: Significant at $p$-value $\leq 0.05$. Negative values for differences favor the intervention group. 
Table 4 Comparison of mean \pm SD scores of overall self-efficacy and health promotion behavior constructs before and after intervention between hemorrhagic and ischemic groups

\begin{tabular}{|l|l|l|l|l|}
\hline Variables & $\begin{array}{l}\text { Hemorrhagic } \\
\text { Mean } \pm \text { SD }\end{array}$ & $\begin{array}{l}\text { Ischemic } \\
\text { Mean } \pm \text { SD }\end{array}$ & F-value & -Value \\
\hline Overall self-efficacy & $\mathbf{1 8 . 4 6} \pm \mathbf{1 . 8 5}$ & $\mathbf{1 7 . 6 1} \pm \mathbf{2 . 3 3}$ & $\mathbf{0 . 0 2 0}$ & $\mathbf{0 . 8 8 7}$ \\
\hline \multicolumn{5}{|l|}{} \\
\hline Health promotion behavior constructs & $20.38 \pm 1.60$ & $20.17 \pm 1.63$ & 0.244 & 0.623 \\
\hline 1. Perceived behavior-specific feelings & $27.31 \pm 3.92$ & $26.38 \pm 3.00$ & 2.11 & 0.151 \\
\hline 2. Perceived benefits & $27.69 \pm 4.01$ & $22.49 \pm 3.74$ & 0.095 & 0.759 \\
\hline 3. Perceived barriers & $24.86 \pm 3.65$ & $22.27 \pm 3.96$ & 2.28 & 0.136 \\
\hline 4. Perceived self-efficacy & $10.92 \pm 1.49$ & $10.47 \pm 1.24$ & 6.08 & 0.017 \\
\hline 5. Activity-related effect & $12.46 \pm 2.40$ & $12.38 \pm 3.17$ & 3.27 & 0.076 \\
\hline 6. Interpersonal influence & $6.76 \pm 1.64$ & $6.25 \pm 1.17$ & 6.51 & 0.013 \\
\hline 7. Situational influence & $12.08 \pm 2.04$ & $14.02 \pm 3.35$ & 0.157 & 0.694 \\
\hline 8. Commitment to action & & \\
\hline
\end{tabular}

Abbreviation: SD, standard deviation.

Note: Significant at $p$-value $\leq 0.05$.

aNCOVA.

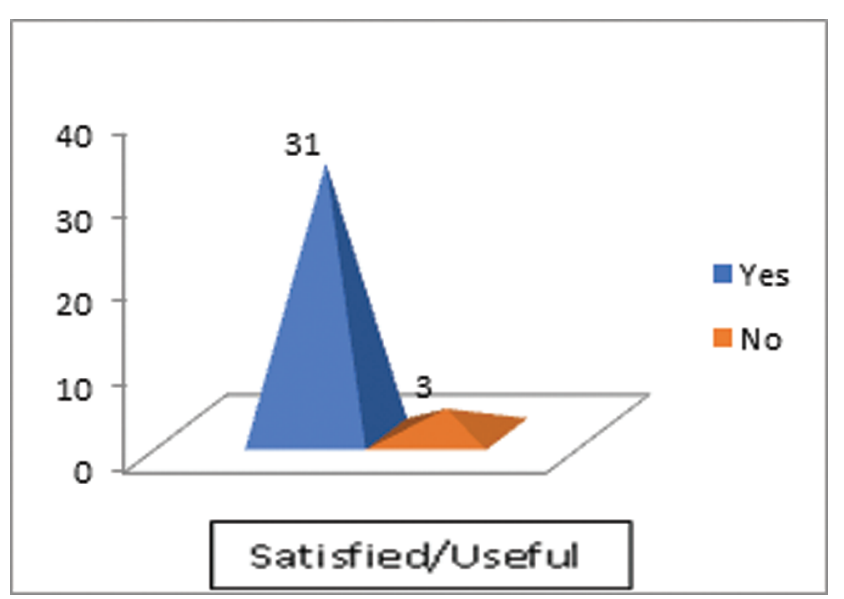

Fig. 2 Caregivers' level of satisfaction with HPM-VLM. HPM-VLM, health promotion model-based visual learning module.

randomization, which causes an increased risk of selection bias and limits the generalizability of study findings. The other limitation was the dependency on the self-reported method of data collection, which could have the risk of reporting bias.

\section{Conclusion}

Self-efficacy and health promotion behavior is crucial to prevent stroke recurrence and effective management of stroke survivors. HPM-VLM was found significantly effective in the promotion of self-efficacy and health promotion behavior among stroke survivors. HPM-VLM must be an integral part of discharge teaching for stroke survivors or their families for effective rehabilitation and stroke recurrence prevention.

\section{Funding}

None.

\section{Conflict of Interest}

None declared.

\section{References}

1 Kang YN, Shen HN, Lin CY, et al. Does a Mobile app improve patients' knowledge of stroke risk factors and health-related quality of life in patients with stroke? A randomized controlled trial. BMC Med Inform Decis Mak 2019;19(1):282-290

2 World Health Organization. Global Burden of Disease (GBD). Available at: www.who.int.access.lib rary.unisa.edu.au/ healthinfo/bod/en/index.html. Accessed April 19, 2020

3 Abd El-Hay SA, Abed Allah AK, Tag El Din ESA. Effect of implementing designed educational training program for neurological nurses on clinical outcomes of stroke patients. Clin Nurs Stud 2018;6(12):121

4 The Economic Times. The stroke disease burden in India has increased nearly 100\%: Indian Stroke Association. 2019

5 Tseng $\mathrm{M}-\mathrm{C}$, Lin $\mathrm{H}-\mathrm{J}$. Readmission after hospitalization for stroke in Taiwan: results from a national sample. J Neurol Sci 2009;284(1-2):52-55

6 Aarnio K, Haapaniemi E, Melkas S, Kaste M, Tatlisumak T, Putaala J. Long-term mortality after first-ever and recurrent stroke in young adults. Stroke 2014;45(9):2670-2676

7 Park JH, Ovbiagele B. Relationship of functional disability after a recent stroke with recurrent stroke risk. Eur J Neurol 2016;23(2):361-367

8 Maasland L, Brouwer-Goossensen D, den Hertog HM, Koudstaal PJ, Dippel DWJ. Health education in patients with a recent stroke or transient ischaemic attack: a comprehensive review. Int J Stroke 2011;6(1):67-74

9 Mudgal SK. Assess learning needs of nursing students and effectiveness of workshop on knowledge regarding extended and expanded role of nurses. Int J Nurs Educ 2018;10(3):109-113

10 Rouholamini S, Gheibizadeh M, Maraghi E, Jahanshahi A. The effects of a training program based on the health promotion model on physical activity in women with type 2 diabetes: a randomized controlled clinical trial. Iran J Nurs Midwifery Res 2020;25(3):224-231

11 Mohammadi, Zeidi I, Alijanzadeh M, Pakpour A. Factors predicting oral health-related behaviors in diabetic patients using 
Pender's Oral Health Promotion Model. J Isfahan Dent Sch 2016;12:183-198

12 Mohsenipouya H, Majlessi F, Shojaeizadeh D, Rahimiforooshani A. The effect of educational intervention based on the Pender's Health Promotion Model on patients' self-efficacy for self-care behaviors following heart surgery. IJNR 2017;12:16-23

13 Sharma SK, Mudgal SK, Thakur K, Gaur R. How to calculate sample size for observational and experimental nursing research studies? Natl J Physiol Pharm Pharmacol 2020;10(1):1-8

14 Baecke JA, Burema J, Frijters JE. A short questionnaire for the measurement of habitual physical activity in epidemiological studies. Am J Clin Nutr 1982;36(5):936-942

15 Brouwer-Goossensen D, van Genugten L, Lingsma HF, Dippel DWJ, Koudstaal PJ, den Hertog HM. Self-efficacy for health-related behaviour change in patients with TIA or minor ischemic stroke. Psychol Health 2018;33(12):1490-1501

16 Wang Q, Chair S, Wong E. Effectiveness of a health promotion programme on self-efficacy and practice of exercise in Chinese metabolic syndrome population: a single-centre, open-label, randomised controlled trial. Lancet 2016;388:S81

17 Guedes NG, Moreira RP, Cavalcante TF, de Araujo TL, Ximenes LB. Students' physical activity: an analysis according to Pender's health promotion model. Rev Esc Enferm USP 2009;43(4):774-780

18 Heydari H, Sharifirad GH, Kamran A. Assessment of physical activity status in patients with type 2 diabetes based on Tran Theoretical model. J Health Syst Res 2014;10:429-441

19 Taymoori P, Niknami SH, Ghofranipour F. Effects of a schoolbased intervention on the basis of Pender's health promotion model to improve physical activity among high school girls. Armaghane Danesh 2007;12(2):47-59

20 Zamani N, Ahmadi Tabatabaei SV, Khanjani N, FadakarDavarani MM. The effect of educational intervention based on the health belief model on medication adherence among patients with diabetes referred to a diabetes center in Zarand, Kerman. J Health Dev 2017;6:97-109

21 Rahimian M, Mohammadi M, Mehri A, Rakhshani MH. Impact of performing health promotion model intervention on physical activity of health volunteer of Torbat-E-Jam City, Iran. Int Arch Health Sci. 2016;3:87-91

22 Mohamadian H, Eftekhar H, Rahimi A, Mohamad HT, Shojaiezade D, Montazeri A. Predicting health-related quality of life by using a health promotion model among Iranian adolescent girls: a structural equation modeling approach. Nurs Health Sci 2011;13(2):141-148

23 Ho AY, Berggren I, Dahlborg-Lyckhage E. Diabetes empowerment related to Pender's Health Promotion Model: a meta-synthesis. Nurs Health Sci 2010;12(2):259-267

24 McGuire AM, Anderson DJ, Fulbrook P. Perceived barriers to healthy lifestyle activities in midlife and older Australian women with type 2 diabetes. Collegian 2014;21(4):301-310

25 Sevinç S, Argon G. Application of Pender's Health Promotion Model to post-myocard infarction patients in Turkey. Int J Caring Sci. 2018;11(1):1209-1218

26 Khodaveisi M, Omidi A, Farokhi S, Soltanian AR. The effect of Pender's Health Promotion Model in improving the nutritional behavior of overweight and obese women. Int J Community Based Nurs Midwifery 2017;5(2):165-174

27 Shojaei S, Farhadloo R, Aein A, Vahedian M. Effects of the health belief model (HBM)-based educational program on the nutritional knowledge and behaviors of CABG patients. J Tehran Heart Cent 2016;11(4):181-186

28 Harvey JN, Lawson VL. The importance of health belief models in determining self-care behaviour in diabetes. Diabet Med 2009;26(1):5-13

29 Shao C, Wang J, Liu J, Tian F, Li H. Effect of a Health Belief Model-based education program on patients' belief, physical activity, and serum uric acid: a randomized controlled trial. Patient Prefer Adherence 2018;12:1239-1245

30 Pitthayapong S, Thiangtam W, Powwattana A, Leelacharas S, Waters CM. A Community based program for family caregivers for post stroke survivors in Thailand. Asian Nurs Res (Korean Soc Nurs Sci) 2017;11(2):150-157 